2 Factors Affecting Sustainable Apparel Consumption

3 in Emerging Countries: A Systematic Literature

\title{
4 Review
}

\author{
Nornajihah Nadia Hasbullah ${ }^{1}$, Zuraidah Sulaiman ${ }^{2 *}$ and Adaviah Mas'od ${ }^{3,}$ \\ 1 Azman Hashim International Business School, Universiti Teknologi Malaysia, 81310, Johor, Malaysia \\ najihahnadya@yahoo.com.my \\ 2 Azman Hashim International Business School, Universiti Teknologi Malaysia, 81310, Johor, Malaysia \\ zuraidahs@utm.my \\ 3 Azman Hashim International Business School, Universiti Teknologi Malaysia, 81310, Johor, Malaysia \\ adaviah@utm.my \\ * Correspondence: zuraidahs@utm.my; Tel.: +60178410849
}

\begin{abstract}
The growth of sustainable apparels provides grounding for the emergence of a new consumer market. Surprisingly, this movement has not only taken place in developed countries but also in emerging countries. To the best of the authors' knowledge, no systematic reviews have been carried out on sustainable apparels, focused specifically on emerging countries. The goal of this systematic review is to analyse the existing literature on various factors that influence sustainable apparel consumption in emerging countries, as well as presenting future research directions. This detailed literature review is guided by the PRISMA Statement (Preferred Reporting Items for Systematic reviews and Meta-Analyses) review method, and its searches encompass sources such as Web of Science, Scopus and Google Scholar databases which, in result, identified 19 related studies. Furthermore, the reviewers segregated the factors into four major domains which include value, subjective norm, perceived behavioural control and knowledge. The results of this review demonstrate that most customers in the emerging countries have already experienced a growing interest in sustainable apparel with a strong development of knowledge, great concern, values and social circle. In sum, this systematic literature review provides an insightful information about sustainable apparel purchase behaviour and helps academicians, manufacturers and retailers to position and market their sustainable clothing brands.
\end{abstract}

Keywords: Sustainable Apparel Consumption; Emerging Countries; Value; Subjective Norm; Perceived Behavioural Control; Knowledge

\section{Introduction}

Sustainability is a much more critical issue in emerging countries compared to developed countries $[16,66]$. This is consistent with the reasoning that most manufacturers of international brands are built in emerging countries, which leading them to a several environmental issues. Meanwhile, the availability of fashion apparel collections everywhere, with good offers and designs, coupled with an exciting shopping experience intrigue impulsive customers in emerging markets to do more shopping [20]. The improving personal financial status and increasing standard of living have increased customers' buying power and lead them to excessive shopping [37]. In return, over consumption occurred and contribute to environmental deterioration. It is quite surprising that, the 
fashion industry has been labeled as the second largest polluting industry after oil [50]. Concurrently, the awareness on the importance of sustainable consumption perspective has received increased attention. In the apparel and textile industry, manufacturers and companies are increasingly embracing eco-friendly components in their apparel product lines in response to an increasing number of people becoming cognisant to environmental-friendly products [24,67]. Meanwhile, the global efforts are seen with the inclusion of the fashion industry in the list of UN's 17 Sustainable Development Goals (SDGs). This global effort has a mission to bring sustainable fashion to the forefront and demonstrate the achievement of many other sustainable development goals. Another positive movement is also organised by a non-profit global organisation called Fashion Revolution. This movement stands together in order to reform the fashion industry and highlight the element of transparency in the fashion supply chain. Interestingly, most of global efforts focused exclusively on the fashion industry are supported by most emerging countries. The State of Fashion Report (2017) prepared by [4] revealed the fact that almost 65 percent of consumers in emerging markets are already actively seeking sustainable fashion. However, this is an interesting fact; although consumers may favour sustainability, they often show attitude-behaviour gaps that inhibit the sustainable fashion market [47]. Despite widespread consumer concerns about sustainability, few consumers purchase sustainable fashions [39].

Therefore, this study aims, for the first time, to shed light on prevailing motives and factors affecting sustainable apparel consumption by systematically reviewing empirical literature covering emerging countries context. Furthermore, the reviewers have identified and classified four specific, main themes of sustainable apparel factors, including value; subjective norm; perceived behavioural control; knowledge, and the selected journal articles were categorised accordingly. After the introduction, the remainder of the paper is structured as follows: Section 2 is devoted to explain the methodological approach to analyse the current state of literature. Section 3 details the results according to different analysed variables. Meanwhile, Section 4 discusses several factors that contributing to the trend extracted from different emerging countries. Finally, Section 5 presents the conclusions and future research directions.

\section{Methodology}

This systematic review was conducted in accordance to the Preferred Reporting Items for Systematic reviews and Meta-Analyses (PRISMA) standard (Moher et al., 2009). In line with this guideline, four steps of review methodology were assessed including identification, screening, eligibility and inclusion. This review was performed on April 2019 and involves studies on the topic of sustainable apparel published between 2015 and 2019. With regard to this timeline, a period of five years is selected as an adequate period of time to see the evolution of this new sustainable trend. As a part of the identification step, three research databases (WEB OF SCIENCE, SCOPUS, GOOGLE SCHOLAR) were used to conduct literature searches, with several keywords used separately and as combinations to search for relevant articles (see Figure 1). Some identified keywords used for the search process are adopted based on previous studies and thesaurus, particularly keywords that are similar and related to sustainable apparel studies (see Figure 1). After the search of databases and the exclusion of the duplication, 1,524 articles were identified. The second step consisted of screening the abstracts of the selected records and excluding them if they did not meet the selection criteria. The purpose of using the inclusion and exclusion criteria is to screen the titles or abstracts. Through the 
83

84

85

86

87

88

89

90

screening process, only 55 articles remained, and 1,469 articles were excluded. The reason of the exclusion is the unmet of the inclusion criteria in terms of publication years, categories, document types, countries and language. Additionally, 19 full-text articles were assessed for eligibility. The remaining 37 journal articles were excluded due to the irrelevance to consumer behaviour, decisionmaking process, unavailability of relevant data and irrelevance of the topics to sustainable apparels. Finally, 19 articles were selected for the review, consist of two qualitative studies, 16 quantitative studies and onemixed method study. As shown in Figure 1, the reviewer presented the flow diagram by following the application of PRISMA.

List of Tables and Figures.

Keywords used to search titles, abstracts and full content included:

TS= ( ( sustainab* OR ethical OR slow OR eco OR "environment" friendly" OR secondhand OR swapping OR recycle* OR upcycle*) AND ( fashion OR clothing OR apparel OR garment OR textile OR sportwear* OR outfit* OR costume OR attire ) AND ( behaviour OR "purchas" behaviour" OR "purchase intention"))

TITLE-ABS-KEY ( ( sustainab* OR ethical OR slow OR eco OR "environment" friendly" OR secondhand OR swapping OR recycle* OR upcycle*) AND (fashion OR clothing OR apparel OR garment OR textile OR sportwear* OR outfit* OR costume OR attire) AND (behaviour OR "purchas" behaviour" OR "purchase intention" ))

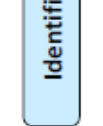

Records after duplicates removed $(\mathrm{n}=1524)$

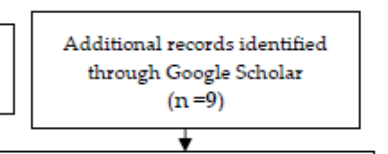

Records and abstracts screened $(n=55)$

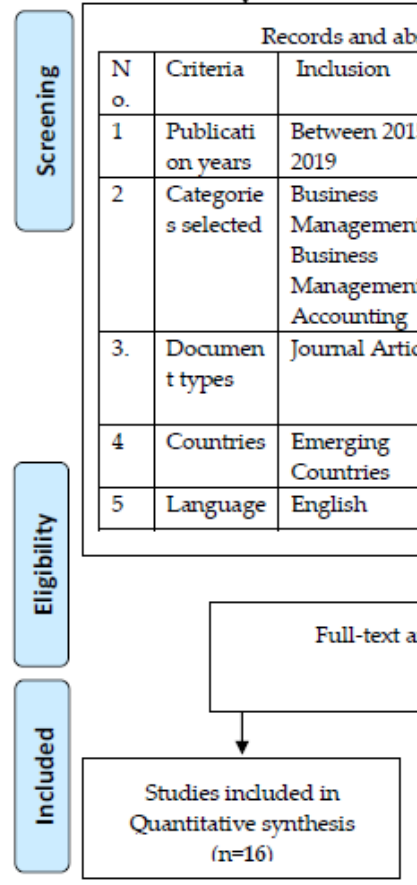
Exclusion

\begin{tabular}{l|l} 
& Exclusion \\
\hline Less than 2015
\end{tabular}
Other than Business Management and Accounting

Journals (systematic review), book series, chapter book, conference proceeding Non-Emerging Countries

Non-English

iness

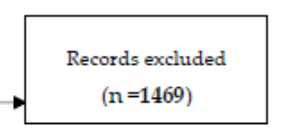

Full-text articles excluded, with reasons ( $n=36)$

Irrelevant to consumer behaviour study Not related to decision making process

Unable to be categories into four categories of sustainable apparel Relevant data not available

Figure 1. PRISMA Flowchart of the study (Adapted from Moher et al., 2009).

\section{Results}

The results of the review are presented in four themes to reflect several factors influencing sustainable apparel purchase intentions and behaviour. A compendium of individual-level consumer behaviour in this study are analysed based on the four themes which comprise of value; social norm; perceived behavioural control; knowledge (see Table 1). Each of the theme is synthesised based on 
98

several behavioural theories including Theory Reasoned Action [18], Theory Planned Behaviour [2] and Theory Consumption Value [53]. All these theories have been adopted in order to get a better understanding about the consumers' decision-making. To shed light on research questions and knowledge gap, this study reviewed the previous studies related to sustainable apparel with inclusion of recycled, organic, vintage, vegan, artisan, locally made, custom-made and fair-trade certified. At the same time, the factors and drivers that lead to this positive movement are identified.

Table 1. Summary of previous sustainable apparel researches.

\begin{tabular}{|c|c|c|c|c|c|c|c|c|c|c|c|c|}
\hline No & Authors & Method & Countries & $\mathrm{V}$ & $\mathrm{A}$ & SN & PBC & $\mathrm{EC}$ & $\mathrm{K}$ & PI & $\mathrm{BH}$ & WTP \\
\hline 1 & {$[14]$} & QN & South Africa & $\sqrt{ }$ & & & & & & $\sqrt{ }$ & $\sqrt{ }$ & \\
\hline 2 & [43] & $\widehat{\mathrm{QL}}$ & South Africa & $\sqrt{ }$ & $\sqrt{ }$ & & & & & & $\sqrt{ }$ & \\
\hline 3 & [57] & $\widehat{\mathrm{QN}}$ & South Africa & & $\sqrt{ }$ & $\sqrt{ }$ & $\sqrt{ }$ & $\sqrt{ }$ & & $\sqrt{ }$ & & \\
\hline 4 & {$[17]$} & QN & Hong Kong, China & & & & & & $\sqrt{ }$ & & $\sqrt{ }$ & \\
\hline 5 & [43] & QN & China & $\sqrt{ }$ & & $\sqrt{ }$ & & $\sqrt{ }$ & & $\sqrt{ }$ & & \\
\hline 6 & [55] & MM & South Korea & & $\sqrt{ }$ & & & & & $\sqrt{ }$ & $\sqrt{ }$ & \\
\hline 7 & {$[22]$} & QL & South Korea & & & $\sqrt{ }$ & & & $\sqrt{ }$ & & & $\sqrt{ }$ \\
\hline 8 & [45] & QN & South Korea, China, Japan & & & & & $\sqrt{ }$ & $\sqrt{ }$ & $\sqrt{ }$ & & \\
\hline 9 & [36] & $\mathrm{QN}$ & India & & & $\sqrt{ }$ & & $\sqrt{ }$ & & & $\sqrt{ }$ & \\
\hline 10 & [39] & QN & South Korea & & $\sqrt{ }$ & $\sqrt{ }$ & & & $\sqrt{ }$ & $\sqrt{ }$ & & \\
\hline 11 & [29] & QN & South Korea & & & $\sqrt{ }$ & & $\sqrt{ }$ & & & $\sqrt{ }$ & \\
\hline 12 & {$[21]$} & QN & South Korea & & & & & $\sqrt{ }$ & & & $\sqrt{ }$ & \\
\hline 13 & [42] & QN & China & & & & & & & $\sqrt{ }$ & & \\
\hline 14 & [6] & $\mathrm{QN}$ & United States and China & & $\sqrt{ }$ & $\sqrt{ }$ & $\sqrt{ }$ & & $\sqrt{ }$ & $\sqrt{ }$ & & \\
\hline 15 & {$[60]$} & QN & India & $\sqrt{ }$ & $\sqrt{ }$ & $\sqrt{ }$ & & & & $\sqrt{ }$ & & \\
\hline 16 & [23] & QN & $\begin{array}{l}\text { United States and South } \\
\text { Korea }\end{array}$ & & & $\sqrt{ }$ & $\sqrt{ }$ & & & $\sqrt{ }$ & & \\
\hline 17 & {$[11]$} & QN & China & & $\sqrt{ }$ & $\sqrt{ }$ & $\sqrt{ }$ & & $\sqrt{ }$ & $\sqrt{ }$ & & \\
\hline 18 & {$[63]$} & QN & Malaysia & & $\sqrt{ }$ & & & & $\sqrt{ }$ & & $\sqrt{ }$ & \\
\hline 19 & {$[64]$} & QN & China & & & $\sqrt{ }$ & & & & & $\sqrt{ }$ & \\
\hline
\end{tabular}

Factors: V= Value; $\mathrm{A}=$ Attitude; $\mathrm{SN}=$ Subjective Norm; $\mathrm{PBC}=$ Perceived Behavioural Control; $\mathrm{EC}=$ Environmental Concern; $\mathrm{K}=$ Knowledge; $\mathrm{PI}=$ Purchase Intention; $\mathrm{BH}=$ Behaviour ; WTP= Willingness to Pay Methods: $\mathrm{QN}=$ Quantitative; $\mathrm{QL}=$ Qualitative; $\mathrm{MM}=$ Mix Method.

\subsection{Sustainable Consumption}

The term of sustainable consumption started to emerge since early 1990 [31]. Sustainable consumption refers to consumption that supports the ability of current and future generations to meet their material and other needs, without causing irreversible damage to the environment or loss of function in natural systems. In a related vein, sustainable consumption also can be described as an aspect of consumer behaviour that involves pre-purchase, purchase and post-purchase components $[32,27]$. In line of reasoning, the reviewer considered the previous journal articles that use sustainable purchase intention, willingness to pay and purchasing behaviour as independent variables. Two articles covered both purchase intention and purchasing behaviour [55, 14], seven articles studied purchasing behaviour [21,63, 36, 64, 17, 48, 29], nine articles studied purchase intention [42, 11, 39, 45, $43,55,60,23,57]$ while one article covered the studied of willingness to pay [22].

\subsection{Sustainable Apparel}


In comprehensive, [26] define sustainable fashion as a concept with the inclusion of myriad

118

119

120

121

122

123

124

125

126

127

128

129

130

131

132

133

134

135

136

137

138

139

140

141

142

143

144

145

146 terms labeled either with recycled, organic, vintage, vegan, artisan, locally made, custom-made or fair-trade certified. In a similar vein, [7] explained the sustainable fashion concept in seven other forms, namely green and clean, on demand and custom made, high quality and timeliness design, fair and ethical, up-cycle, rent, lease, and swap and second-hand fashion. Notably, when individuals start to consciously engage in sustainable apparel consumption, they would purposefully take into consideration about the excessive resources and any negative social impact involved in the production processes. This type of customers make a choice to hinder current or future generations. In Figure 2, the reviewers identified two previous studies focused on slow fashion [14, 42] and collaboration fashion [63,43), while eight previous studies focused on broad sustainable concepts [48, $17,55,22,45,39,29,64]$ and seven eco-conscious apparel [57, 60, 21, 6, 36, 23, 11] Nevertheless, up until now, no studies focused on up-cycled or recycled apparel covered emerging countries context.

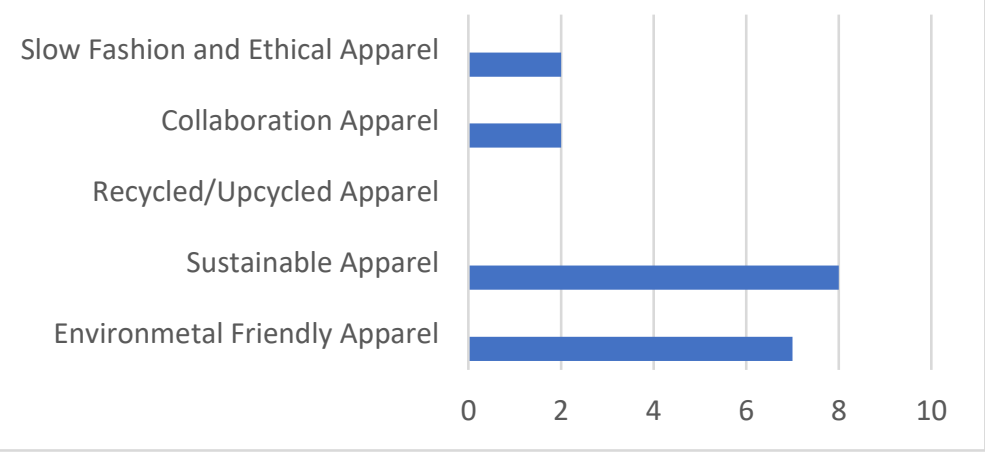

Figure 2. Overview of the sustainable apparel research in Emerging countries.

\subsection{Overview of publication}

\subsubsection{Journal Publication}

The analysis results show that the research articles come from 12 journals. Table 2 summarises all the journal publications. The largest contribution sources are three articles from Journal of Fashion Marketing and Management: An International Journal; the International Journal of Consumer Studies, followed by two articles from Journal of Global Fashion Marketing; Fashion and Textile Journal; Sustainability and one article from the International Journal of Retail and Distribution Management; Journal of Brand Management; SAGE OPEN; Australasian Marketing Journal; Global Business Review; International Journal of Business Society; Journal of Business Research.

Table 2. Summary of Journal Publication of Previous Studies.

\begin{tabular}{|l|l|c|}
\hline No. & Journal Publication & Frequency \\
\hline 1 & International Journal of Retail and Distribution Management & 1 \\
\hline 2 & Journal Brand Management & 1 \\
\hline 3 & International Journal of Consumer Studies & 3 \\
\hline 4 & Journal of Fashion Marketing and Management: An International Journal & 3 \\
\hline 5 & Journal of Global Fashion Marketing & 2 \\
\hline 6 & Fashion and Textiles & 2 \\
\hline 7 & Australasian Marketing Journal & 1 \\
\hline 8 & Global Business Review & 1 \\
\hline 9 & International Journal of Sustainable Society & 1 \\
\hline
\end{tabular}




\begin{tabular}{|l|l|c|}
\hline 10 & Sustainability & 2 \\
\hline 11 & SAGE OPEN & 1 \\
\hline 12 & Journal of Business Research & 1 \\
\hline
\end{tabular}

\subsubsection{Emerging Countries}

Emerging market countries are those that are striving to become developed countries and are generally in line with economically disciplined track. The countries listed as emerging countries are becoming more sophisticated with a positive shifting on fiscal transparency, focus on production, developing regulatory bodies and exchanges, and acceptance of outside investment. Concurrently, emerging countries have found to be the huge changemaker in the consumer market of the whole world. The strength of consumers in emerging markets is estimated at around over 3 billion USD and develop over 80 percent of worldwide consumers. Due to that, developed countries have started to change their direction by following emerging market patterns. On the other hand, it is an utmost important issue to protect the earth's environment by selling green products in emerging countries $[10]$.

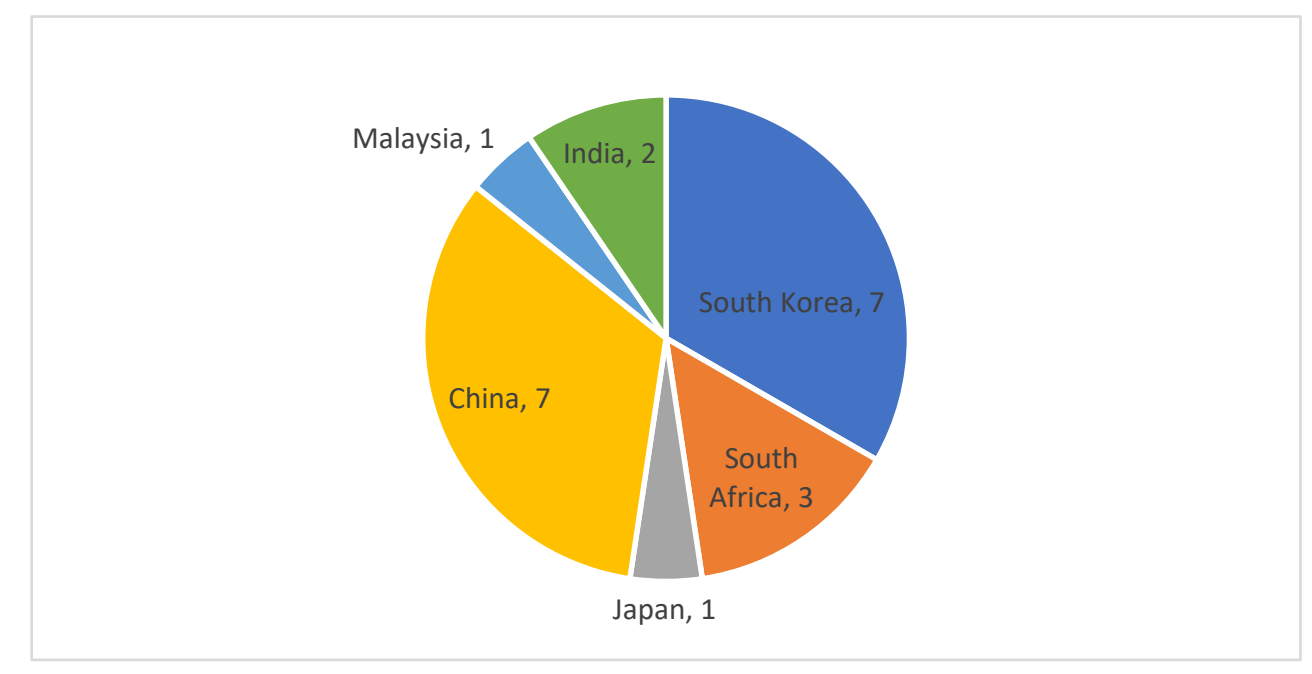

Figure 3. Overview of the research by emerging country.

Based on this systematic literature review, there are only six emerging countries that already discovered sustainable apparel topic. Although the number of countries involved is still small, but it is adequate to get an insight about this positive fashion landscape. As shown in Figure 3, the reviewer identified seven journal articles covered South Korea and China context, three journal articles studied carried out in South Africa, two journal articles studied in India and one journal article studied carried out in Malaysia and Japan. Thus, this review shows that South Korea and China have contributed the highest total number of research papers, while Japan and Malaysia produced only a few numbers of papers that focusing on this topic.

\section{Discussion}

Customer decision to make a sustainable choice affected by a wide range of potential influences. A vast number of previous researches are trying to determine the antecedents for sustainable behavioural intention and actual sustainable behaviour. As a result, consumers' intention to show specific behaviour is often seen as the best predictor for that behaviour. However, as previous research has shown, there is often a gap between consumers' attitudes or intentions to consume in a 
182

183

184

185

186

187

188

189

190

191

192

193

194

195

196

197

198

199

200

201

202

203

sustainable way and their actual purchase behaviour [15, 9]. This so called 'attitude-behaviour-gap' can be found due to various barriers of either external or internal nature. A wider scope of factors might even have to be included when discussing decisions for complex and expensive environmentally significant behaviours [56]. As reasoned above, it is essential to discover sustainable consumption in the scope of sustainable apparel, considering that this fashion trend is a key contributor to this market prospect [47].

Drawing on the insight from the results section, the reviewer will discuss and analyse the existing literature on various factors that influence sustainable apparel consumption in emerging countries. The results of the review are presented in four themes comprised of value, subjective norm, perceived behavioural control and knowledge. Further, the findings and their implications will be discussed in the broadest context and will be highlighted for future research directions.

\subsection{Value}

Consumer values refer to relatively stable conditions as well as beliefs that have a strong motivational impact on consumers' buying behaviour [28]. One of the most popular theory adopted to study value is Theory of Consumption Value (TCV) [53]. This theory has gained special attention and known as a stable construct in predicting consumer buying behaviour [25]. Consumption values explain whether consumers choose to buy a specific product, why consumers choose one product over another and why consumers choose one brand over another [53]. The creation of valuable product will subsequently increase a consumer's intention to purchase and pay a price premium [34]. Nowadays, instead of looking only at fabulous styles and trends, buyers have started to consider about the new direction for authenticity and sustainability [35, 41]. In turn, these real buyers become more selective and aware of issues regarding toxic materials, discharges, and pollution [39].

A past study by [14] covering the South African context exposed that the desire for sustainable, genuine leather products and the consumption of luxury brands involves several dimensions of customers' perceived value dimension $[61,62,65]$ as constructed from the Theory of Consumption Value [53]. It is a belief that South Africa focuses more on functional benefits entailed to quality and durability of products. In line with that, sustainable apparel can be perceived as premium value products which signify timelessness, durability, and quality. [48] agreed that fashion evaluation in South Africa is based more on style, fit, colour and texture. These findings were echoed in the conjoint study results for clothing where the highest value was for fit, followed by price and quality as purchase criteria. In another research initiative by [43], it is revealed that the Post-90s customers in China perceived the strongest hedonic values as well as uniqueness of second-hand clothing. This finding is consistent with the existing literature in which this generation often chooses to forego brand name purchases, in favour of choosing a product that retains the greatest long-term value [13]. Meanwhile, the Post-80s held the highest perceived environmental values as well as uniqueness of second-hand clothing as compared to other cohorts. This observation is in line with the high level of awareness of environmental issues and support for environment protection among Gen $Y$ consumers $[30,51]$ because they grew up in an era when eco-consciousness became a norm. Consistently, [60] study done in the context of India exposed that youths' experience with green products, environmentally friendly values, and awareness of green brands were apparently important. Youths' past experience with other organic products and brands is likely to influence their future intention to purchase similar products. 
Drawing on multiple literature covering the contexts of South Africa, China and India, the countries showed a significant relationship between value and sustainable apparel consumption. In the South African domain, customers are more attracted to the functional benefits. Meanwhile, in the context of China, customers react in a more positive way to collaboration apparel consumption. On the other hand, the Indian landscape shows that customers will only appreciate environmental values after experiencing the quality of the products. To wrap up this section, it can be summarised that environmental issues could be a new source of competitive advantage in business and are shifting focus to provide environmentally conscious consumers with more product options that meet their preferences, reflect their values, and represent their lifestyle.

\subsection{Subjective Norm and Reference Group}

The Theory of Planned Behaviour (TPB) and Theory Reasoned Action (TRA) are relevant in explaining consumers' environmental-friendly purchases [33, 19]. One of the important variables is subjective norm. The subjective norm can be a social pressure acting upon and guiding a behaviour. Social pressure and reference group may also be viewed as the form of belief helping the individuals in arriving at a decision regarding action towards approval or disapproval of a behaviour [2]. As a fruitful theoretical lens, this variable has been adopted in several sustainable apparel studies to understand the emerging market context.

Galvanising consumer interest in this promising market, extant literature mentions, and numerous studies have been done in the South Korean domain. An existing study by [23] revealed that eco-clothing purchase in Korea is strongly influenced by both injunctive and descriptive norms. This result is consistent with the previous researches by $[39,22]$ which reveal that conformity is a crucial factor for people belonging to a collectivistic culture. In the perspective of collectivism, people belong to groups that look after them in exchange for loyalty [28]. Exposure of others that belong to the circle is pivotal in motivating consumers' buying behaviour in a collectivistic culture. Perhaps, the present of moral intensity will show Korean customers concern for others' welfare [29]. [55] asserted that Korean customers are already aware about this positive fashion movement and have been approximately synchronised it with their values and others. In line with the findings of the Korean market, subjective norm also found to have the highest influence on purchase intention in the China context [6]. Similarly, this notion implies that consumers who are more collectivistic perceive higher consumer effectiveness and hold more faith in concerning on eco-clothing purchase benefits for environmental protection [11]. According to [43], the Post-80s in China demonstrated a higher level of descriptive norms, when comparing different generation of customers in the scope of secondhand clothing. This cohort had the highest awareness of friends, family members or other consumers purchasing in owning second-hand clothing. Moreover, the strong practices of Confucian culture lead customers to maintain a good public self-image and indirectly motivate them to purchase sustainable apparel [64]. Another notion of study by [63] covering the Malaysian market showed a significant positive effect of the philanthropic awareness factor that measures the consumers' altruism in clothing disposal practices and their willingness to help the needy. This indicates that philanthropic factors are the most preferred clothing disposal option of young consumers in Malaysia. [1] strongly agreed that the Malaysians expressed their sustainable consumption by motivating their needs in order to connect with others fulfilled and based on their experience. 
Contrarily, a previous study by [57] has shown that social norms, moral norms and controllability are not significant in predicting male consumers' intention to acquire eco-friendly apparel in the context of the emerging of South African market. Respondents' attitudes and selfefficacy are mostly influenced by the dimension of perceived behavioural control contributed to their intention to acquire apparel in a pro-environmental manner. This, in return, encapsulates that brands create an emotional connection with the consumers, and therefore potentially have the power to shift consumers' attitudes and create emotional preferences that influence behaviour [48]. In a similar vein, [36] also pointed out that social influence does not play a role in influencing consumers for the products which are yet to penetrate mass consumers. In such situation, consumers in a collectivistic culture like India tends to exhibit individualistic behaviour. Only a few numbers of early adopters purchase new products because they do not need any social proof and tend to try new products. Therefore, it is asserted that in emerging economies, majority of consumers (except early adopters) purchase organic clothing because of individual-level reasons, such as environmental concerns, health and safety concerns, and sustainability, and excluding the social influence. In other words, the behaviour of consumers will be largely governed by personal motives when the product is at the introductory stage of its life-cycle [58].

It is interesting to note that emerging countries including South Korea, China and Malaysia signify a significant relationship between peer pressure and sustainable apparel consumption. This is pointing to the fact that consumers' purchasing behaviour or intention in a collectivistic culture is mostly influenced by exposure of others that belong to the circle. Therefore, other collectivistic cultures like India and South Africa shift to individualistic behaviour as considering this fashion is still at the nascent stages. The success of sustainable apparel also depends on customers attachment to the product as well as the relevancy of this practices among their own group [12].

\subsection{Knowledge and Environmental Concern}

[44] expressed knowledge as an important role and antecedent to the receiver's capacity to process the information. An earlier study by [38] found that environmental apparel knowledge had a limited relationship with one's environmental concern. In that century, United States college-aged consumers still lacked in considering environmental impacts when it came to clothing purchasing. However, after two decades, this sustainable fashion movement has not only taken place in developed countries, but also in Asia, Latin America and Eastern Europe [5]. This huge shifting occurred when customers are more concerned with the materials and processes as well as the ethical implication of the apparel that they purchase [54, 49, 14].

A recent comparative study carried out by [6] drew a parallel result between the United States and China. It was found that customers in both countries tend to avoid incidences that are harmful to the environment. [43] added, the current sustainable fashion is prevalent in many cities of China, as well as the practice of collaboration fashion. Younger generations are found to have a stronger intention to consume second-hand clothing. Their purchase behaviours may provide a momentum for other Chinese consumers to see the value and reduce concerns of consuming more new clothing. As sustainable fashion covers a wider element of the theme of fashion, [42] recommended this brand to focus on one sustainable key theme. At the same momentum, producers are also able to build knowledge specifically to build trust, respect and improved customer loyalty. [11, 17] argued that the 
lack of specific information provided will make promotional messages less effective in stimulating sustainable behaviours. The scarcity of environmental information also often leads users to find difficulty in understanding this theme and leaving them to advance their own knowledge based on their perspective to fully understand the nature of the message. A similar finding by [29] indicates that the emergence of sustainable apparel in the Korean market is replicated from the rise of environmental knowledge of organic and naturally dyed textile and apparel products. As participants gain more knowledge and experience, the negative emotional state such as guilt will control their emotion easily [21]. Consequently, customers will not feel reluctant to engage with this fashion in the future [22]. Not only South Korea and China, Japan also has a strong level of environmental awareness in terms of environmental concerns, product knowledge and positive perceived benefits [45]. Despite a high level of environmental awareness, some customers still hesitate to purchase sustainable apparels due to the presence of sceptical perspectives regarding its quality and aesthetic value. In conjunction with that, it is essential for businesses to improve the aesthetic aspects and credibility of the products [39].

In the present context of South Africa, [57] found out that gender differences play important roles in influencing their pro-environmental awareness and attentiveness to gain knowledge. The social circle and life experience will influence a belief and attention to acquire more knowledge. Along the same line, [63] exposed that the basic barriers that stopped consumers from recycling their unwanted clothes are embedded from the low level of awareness about sustainable fashion and the knowledge of how and where to dispose their unwanted clothes. In contrast, the study by [60] revealed that green knowledge and peer pressure do not influence organic clothing purchase behaviour in the Indian context. This is consistent with the reasoning that organic clothing purchase decision-making is directed based on the individual's perspective about green attitude and selfconcept.

Taken as a whole, knowledge is the key factor to stimulate customers to act in a sustainable way. Based on this systematic literature review, South Korea, Japan and China have a strong environmental concern, awareness and knowledge regarding sustainable apparel compared to India and South Africa. Perhaps, the presence of positive social circles and life experiences will stimulate a belief and attention to acquire more knowledge. On the basis of foregoing discussion, there is still a lack of in-depth research that covers sustainable knowledge comprehensively taking part in subjective and objective knowledge [39]. The inclusion of this two types of knowledge is pivotal in influencing the decision process differently [8]. Objective knowledge influences search strategies while subjective knowledge gives consumers greater self-confidence and is a predictor of purchase behaviour [52]. In doing so, it is important to include these two types of knowledge in future sustainable apparel studies.

\subsection{Perceived Behavioural Control and Self efficacy}

To improve the explanatory power of TRA, [2] further introduced the TPB by adding another construct named PBC to the TRA. [2] argued that a person's intention to perform a specific behaviour is expected to control the volitional factors. These factors indicate the extent of efforts to make and the degree of willingness to try, by individuals, in order to produce the behaviour [40] . Thus, PBC is defined by behaviour of interest. According to [59] consumers' self-interest is an important 
antecedent which can increase their involvement with eco-friendly apparel. On one hand, the greater behavioural control is perceived by consumers, a stronger positive relationship between attitude and purchase intention is more likely to occur.

In the Chinese context, perceived behavioural control significantly impacts sustainable apparel consumption. This result portrays that Chinese consumers' have a higher level of confidence in translating their intention to purchasing behaviour of eco-apparel lines [6]. This finding is consistent with [23] study which covers the South Korean context. The scholar had shown a direct and strong effect on perceived behavioural control, which means that purchasing behaviours of others influence an individual's perception of ease or difficulty of buying the product. Nevertheless, the study by [57] exposed a different result. The researchers included two dimensions of perceived behavioural control comprising of self-efficacy and controlability. The result of self-efficacy has a positive effect on the male consumers' pro-environmental intent to engage in eco-friendly apparel acquisition, while contradicting with controlability elements. The availability of the eco-apparel in the South African market makes customers unable to consume and experience the quality of this product.

Subsequently, perceived behavioural control gives impact to China, South Africa and South Korea. It shows that these emerging countries have a strong interest and willingness to try this new sustainable fashion apparel.

\section{Conclusions}

This paper has conducted a systematic literature review to analyse previous published research articles that discover factors influencing sustainable apparel consumption in the context of emerging countries. Altogether, only 19 articles were selected and matched the scope of study. Further, the results of the review are presented in four comprehensive themes and explained in-depth based on each emerging country context. Simply, the level of sustainable apparel consumption in emerging countries context can be divided into three categories which are high, middle and low. Japan, South Korea and China can be categorised as the countries who have a high level of acceptance towards this type of product. The customers in these countries shown a consistent significant result in part of high value, knowledge, social norm and perceived behavioural control when dealing with sustainable apparel. This promising fashion already become a culture and a part of them. For a middle level consumption, Malaysia experienced a slow growth but promising progress. With the growing of new start-up entrepreneur and designer who jump into sustainable design including Kloth Malaysia, Real-M, Kanoe, Nukleus, Zibossa, let customers enjoy a variety of collections and styles. At the same time, social circle and environment also play an important role in shaping this positive consumption in Malaysia. Finally, the low-level sustainable apparel consumption are India and South Africa. Some of the main factors that contribute to a low consumption are the irrelevancy of sustainable apparel concepts among their social circle, low level of knowledge and the lack of availability of the product in the present market.

Taken together, this review is beneficial to academician, businesses and manufacturers to learn more about the sustainable apparel landscape in emerging countries while filling more valuable 
insight to increase consumers' interests with sustainable apparel products. However, there are still some limitations that represent potential interesting avenues for future studies. Firstly, it is recommended to examine the different roles of gender, education, income and occupation in influencing the decision to purchase organic clothing. Most of the studies did not focus on understanding the organic clothing purchase behaviour of other age groups and was restricted to youths. Secondly, for a better understanding, the present study could be extended by using other theoretical framework perspectives. In addition to this emerging and potentially promising research direction, it is also recommended for the future researchers to touch other factors that might affect sustainable apparel purchasing decisions, including the availability, premium pricing and style of the apparel. Thus, more researches still need to be carried out in emerging countries in order to get a better understanding about the factors that can influence customers' sustainable apparel consumption.

Author Contributions: Nornajihah Nadia Hasbullah wrote the paper; Zuraidah Sulaiman and Adaviah Mas'od validate and revising the contents.

Funding: This study received no specific financial support.

Acknowledgments: Sincere gratitude goes to my supervisor, Dr. Zuraidah Sulaiman and Dr. Adaviah Mas'od for their guidance, involvement, and dedication in writing this paper. To my family and my Ph.D siblings, thank you very much for your support, time, and knowledge we shared together.

Conflicts of Interest: The authors declare that they have no competing interests.

\section{References}

1. Abdulrazak, S., \& Quoquab, F. (2018). Exploring Consumers' Motivations for Sustainable Consumption: A Self-Deterministic Approach. Journal of International Consumer Marketing, 30(1), 14-28.

2. Ajzen, I. (1991). The Theory of Planned Behavior. Organizational Behavior E Human Decision Processes, 50(2), 179-211.

3. Ajzen, I. (2005). Attitudes, personality, and behavior. McGraw-Hill Education (UK).

4. Amed, I., \& Berg, A. (2017). The state of fashion. Retrieved from https://www.mckinsey.com/ /media/McKinsey/Industries/Retail/Our Insights/The state of fashion/The-state-of-fashion-2017-McK-BoF-report.ashx

5. Bendell, J., \& Kleanthous, A. (2007). Deeper Luxury. Deeper Luxury, 1-47.

6. Bong Ko, S., \& Jin, B. (2017). Predictors of purchase intention toward green apparel products: A crosscultural investigation in the USA and China. Journal of Fashion Marketing and Management: An International Journal, 21(1), 70-87.

7. Brismar, A. (2019). Seven Forms of Sustainable Fashion. Retrieved from http://www.greenstrategy.se/sustainable-fashion/seven-forms-of-sustainable-fashion/

8. Brucks, M. (1985). The effects of product class knowledge on information search behavior. Journal of Consumer Research, 12, 1-16.

9. Carrigan, M., \& Attalla, A. (2001). The myth of the ethical consumer-do ethics matter in purchase behaviour? Journal of Consumer Marketing, 18(7), 560-578.

10. Chen, C. C., Chen, C. W., \& Tung, Y. C. (2018). Exploring the consumer behavior of intention to purchase green products in Belt and Road countries: An empirical analysis. Sustainability (Switzerland), 
10(3).

11. Chi, T., \& Zheng, Y. (2016). Understanding environmentally friendly apparel consumption: an empirical study of Chinese consumers. International Journal of Sustainable Society, 8(3), 206.

12. Ciasullo, M. V., Maione, G., Torre, C., \& Troisi, O. (2017). What about sustainability? An empirical analysis of consumers' purchasing behavior in fashion context. Sustainability (Switzerland), 9(9), 1-18.

13. Daily, J. (2012). Brands struggle to connect with China's "Post-90s" generation'. Retrieved from https://jingdaily.com/brandsstruggle-\%0Ato-connect-with-chinas-post-90s-generation/

14. de Klerk, H. M., Kearns, M., \& Redwood, M. (2019). Controversial fashion, ethical concerns and environmentally significant behaviour: The case of the leather industry. International Journal of Retail and Distribution Management, 47(1), 19-38.

15. Devinney, T. M., Auger, P., \& Eckhardt, G. M. (2010). The myth of the ethical consumer hardback with DVD. Cambridge University Press.

16. Doh, J. P., Littell, B., \& Quigley, N. R. (2015). CSR and sustainability in emerging markets: Societal, institutional, and organizational influences. Organizational Dynamics, 2(44), 112-120.

17. Evans, S., \& Peirson-Smith, A. (2018). The sustainability word challenge: Exploring consumer interpretations of frequently used words to promote sustainable fashion brand behaviors and imagery. Journal of Fashion Marketing and Management, 22(2), 252-269.

18. Fishbein, M., \& Ajzen, I. (1975). Intention and Behavior: An introduction to theory and research.

19. Groening, C., Sarkis, J., \& Zhu, Q. (2018). Green marketing consumer-level theory review: A compendium of applied theories and further research directions. Journal of Cleaner Production, 172.

20. Gwilt, A., \& Rissanen, T. (2011). Introduction from the Editors. Shaping sustainable fashion: changing the way we make and use clothes. Earthscan, London, 13-14.

21. Ha, S., \& Kwon, S. Y. (2016). Spillover from past recycling to green apparel shopping behavior: the role of environmental concern and anticipated guilt. Fashion and Textiles, 3(1).

22. Han, J., Seo, Y., \& Ko, E. (2017). Staging luxury experiences for understanding sustainable fashion consumption: A balance theory application. Journal of Business Research, 74, 162-167.

23. Han, T. I. (2018). Determinants of organic cotton apparel purchase: A comparison of young consumers in the U.S.A. and South Korea. Sustainability (Switzerland), 10(6).

24. Hardin, I. R., Wilson, S. S., Dhandapani, R., \& Dhende, V. (2009). An assessment of the validity of claims for "bamboo" fiber. AATCC Review, 9(10), 33-36.

25. Hellier, P. K., Geursen, G. M., Carr, R. A., \& Rickard, J. A. (2003). Customer repurchase intention: A general structural equation model. European Journal of Marketing, 37(11/12), 1762-1800.

26. Henninger, C. E., Alevizou, P. J., \& Oates, C. J. (2016). What is sustainable fashion? Journal of Fashion Marketing and Management: An International Journal, 20(4), 400(4), 400-416.

27. Hiller, A. J. (2010). Challenges in researching consumer ethics: A methodological experiment. Qualitative Market Research: An International Journal, 13(3), 236-252.

28. Hofstede, G. (2001). Culture's consequences: Comparing values, behaviors, institutions and organizations across nations. Sage publications.

29. Hong, H., \& Kang, J. H. (2019). The impact of moral philosophy and moral intensity on purchase behavior toward sustainable textile and apparel products. Fashion and Textiles, 6(1).

30. Hymas, L. (2011). Gen $Y$ and Gen X get it right on the environment; old folks don't. Retrieved from http://grist.org/climate-energy/2011-11-\%0A07-gen-y-and-gen-x-get-it-right-on-the-environment-oldfolks-dont/ 
31. Jackson, T. (2004). Negotiating Sustainable Consumption: A review of the consumption debate and its policy implications. Energy \& Environment, 15(6), 1027-1051.

32. Jacoby, J., Chestnut, R. W., \& Silberman, W. (1977). Consumer use and comprehension of nutrition information. Journal of Consumer Research, 4(2), 119-128.

33. Janmaimool, P. (2017). Application of protection motivation theory to investigate sustainable waste management behaviors. Sustainability (Switzerland), 9(7), 1-16.

34. Jung, S., \& Jin, B. (2016). Sustainable development of slow fashion businesses: Customer value approach. Sustainability (Switzerland), 8(6).

35. Kapferer, J. N., \& Michaut, A. (2015). Luxury and sustainability: a common future? The match depends on how consumers define luxury. Luxury Research Journal, 1(1), 3-17.

36. Khare, A., \& Varshneya, G. (2017). Antecedents to organic cotton clothing purchase behaviour: study on Indian youth. Journal of Fashion Marketing and Management: An International Journal, 21(1), 51-69.

37. Kim, A. J., \& Ko, E. (2012). Do social media marketing activities enhance customer equity? An empirical study of luxury fashion brand. Journal of Business Research, 65(10), 1480-1486.

38. Kim, H. S., \& Damhorst, M. L. (1998). Environmental concern and apparel consumption. Clothing and Textiles Research Journal, 16(3), 126-133.

39. Kong, H. M., Ko, E., Chae, H., \& Mattila, P. (2016). Understanding fashion consumers' attitude and behavioral intention toward sustainable fashion products: Focus on sustainable knowledge sources and knowledge types. Journal of Global Fashion Marketing, 7(2), 103-119.

40. Kotler, P., \& Lee, N. (2008). Social marketing: Influencing behaviors for good. Sage.

41. Kumar, V. (2018). Transformative Marketing: The Next 20 Years. Journal of Marketing, 82(4), 1-12.

42. Lee, J., \& Lee, Y. (2015). The interactions of CSR, self-congruity and purchase intention among Chinese consumers. Australasian Marketing Journal, 23(1), 19-26.

43. Liang, J., \& Xu, Y. (2018). Second-hand clothing consumption: A generational cohort analysis of the Chinese market. International Journal of Consumer Studies, 42(1), 120-130.

44. MacInnis, D. J., Moorman, C., \& Jaworski, B. J. (1991). Enhancing and Measuring Consumers' Motivation, Opportunity, and Ability to Process Brand Information from Ads. Journal of Marketing, 55(4), 32.

45. Min Kong, H., \& Ko, E. (2017). Why do consumers choose sustainable fashion? A cross-cultural study of South Korean, Chinese, and Japanese consumers. Journal of Global Fashion Marketing.

46. Moher, D., Liberati, A., Tetzlaff, J., \& Altman, D. G. (2009). (2009). Preferred reporting items for systematic reviews and meta-analyses: the PRISMA statement. Annals of Internal Medicine, 151.(4), 264269.

47. Niinimäki, K. (2010). Eco-Clothing, consumer identity and ideology. Sustainable Development, 18(March), 150-162.

48. Nilssen, R., Bick, G., \& Abratt, R. (2019). Comparing the relative importance of sustainability as a consumer purchase criterion of food and clothing in the retail sector. Journal of Brand Management, 26(1), 71-83.

49. Powell, B., \& Zwolinski, M. (2012). The Ethical and Economic Case Against Sweatshop Labor: A Critical Assessment. Journal of Business Ethics, 107(4), 449-472.

50. Qutab, M. (2017). What's the Second Most Polluting Industry? (We'll Give You A Hint - You're Wearing It). Retrieved from https://www.onegreenplanet.org/environment/clothing-industry-second-mostpolluting/ 
51. Rayapura, A. (2014). Millennials most sustainability-conscious generation yet, but don't call them 'environmentalists'. Retrieved from http://www.sustainablebrands.com/news_and_views/\%0Astakeholder_trends_insights/aarthi_rayapu ra/millennials_most_sustainability_\%0Aconscious

52. Selnes, F. (1986). Subjective and objective measures of product knowledge contrasted. ACR North American Advances.

53. Sheth, J. N., Newman, B. I., \& Gross, B. L. (1991). Why We Buy What We Buy: A Theory of Consumption Values: Discovery Service for Air Force Institute of Technology. Journal of Business Research, 22(2), 159170.

54. Snyder, J. (2010). Exploitation and Sweatshop Labor: Perspectives and Issues. Business Ethics Quarterly, 20(2), 187-213.

55. Song, S., \& Ko, E. (2017). Perceptions, attitudes, and behaviors toward sustainable fashion: Application of Q and Q-R methodologies. International Journal of Consumer Studies, 41(3), 264-273.

56. Stern, P. C. (2000). New environmental theories: toward a coherent theory of environmentally significant behavior. Journal of Social Issues, 56(3), 407-424.

57. Taljaard, H., Sonnenberg, N. C., \& Jacobs, B. M. (2018). Factors motivating male consumers' eco-friendly apparel acquisition in the South African emerging market. International Journal of Consumer Studies, 42(5), 461-468.

58. Thøgersen, J., \& Zhou, Y. (2012). Chinese consumers' adoption of a 'green'innovation-The case of organic food. Journal of Marketing Management, 28(3-4), 313-333.

59. Tung, T., Koenig, H. F., \& Chen, H. L. (2017). Effects of green self-identity and cognitive and affective involvement on patronage intention in eco-friendly apparel consumption: A gender comparison. Sustainability (Switzerland), 9(11).

60. Varshneya, G., Pandey, S. K., \& Das, G. (2017). Impact of Social Influence and Green Consumption Values on Purchase Intention of Organic Clothing: A Study on Collectivist Developing Economy. Global Business Review, 18(2), 478-492.

61. Vigneron, F., \& Johnson, L. W. (1999). A Review and a Conceptual Framework of Prestige-Seeking Consumer Behavior. Academy of Marketing Science Review, 1(1), 1-15.

62. Vigneron, F., \& Johnson, L. W. (2004). Measuring perceptions of brand luxury. Journal of Brand Management, 11(6), 484-506.

63. Wai Yee, L., Hassan, S. H., \& Ramayah, T. (2016). Sustainability and Philanthropic Awareness in Clothing Disposal Behavior Among Young Malaysian Consumers. SAGE Open, 6(1).

64. Wei, X., \& Jung, S. (2017). Understanding Chinese consumers' intention to purchase sustainable fashion products: The moderating role of face-saving orientation. Sustainability (Switzerland), 9(9).

65. Wiedmann, K. P., Hennigs, N., \& Siebels, A. (2009). Value-based segmentation of luxury consumption behavior. Psychology and Marketing, 26(7), 625-651.

66. Yang, S., Song, Y., \& Tong, S. (2017). Sustainable retailing in the fashion industry: A systematic literature review. Sustainability (Switzerland), 9(7), 1-19.

67. Young, W., Hwang, K., McDonald, S., \& Oates, C. J. (2010). Sustainable consumption: green consumer behaviour when purchasing products. Sustainable Development, 18(1), 20-31. 